\title{
Direct Measurement of Strontium-90 and Uranium-238 in Soils on a Real- Time Basis: 1994 Summary Report
}
A. J. Schilk
C. W. Hubbard
M. A. Knopf
R. C. Thompson

April 1995

Prepared by the the U.S. Department of Energy under Contract DE-AC06-76RLO 1830

Funded by the Office of Technology Development, within the U.S. Department of Energy's Office of Environmental Management, under the Characterization, Monitoring, and Sensors Integrated Program

Pacific Northwest Laboratory

Operated for the U.S. Department of Energy by Battelle Memorial Institute 


\title{
DISCLAIMER
}

This report was prepared as an account of work sponsored by an agency of the United States Government. Neither the United States Government nor any agency thereof, nor Battelle Memorial Institute, nor any of their employees, makes any warranty, expressed or implied, or assumes any legal liability or responsibility for the accuracy, completeness, or usefulness of any information, apparatus, product, or process disclosed, or represents that its use would not infringe privately owned rights. Reference herein to any specific commercial product, process, or service by trade name, trademark, manufacturer, or otherwise does not necessarily constitute or imply its endorsement, recommendation, or favoring by the United States Government or any agency thereof, or Battelle Memorial Institute. The views and opinions of authors expressed herein do not necessarily state or reflect those of the United States Government or any agency thereof.

\author{
PACIFIC NORTHWEST LABORATORY \\ operated by \\ BATTELLE MEMORIAL INSTITUTE \\ for the \\ UNITED STATES DEPARTMENT OF ENERGY \\ under Contract DE-AC06-76RLO 1830
}

Printed in the United States of America

Available to DOE and DOE contractors from the

Office of Scientific and Technical Information, P.O. Box 62, Oak Ridge, IN 37831;

prices available from (615) 576-8401. FTS 626-8401.

Available to the public from the National Technical Information Service,

U.S. Department of Commerce, 5285 Port Royal Rd., Springfield, VA 22161. 


\author{
A.J. Schilk \\ C.W. Hubbard \\ M.A. Knopf \\ R.C. Thompson
}

April 1995

Prepared for the U.S. Department of Energy under Contract DE-AC06-76RLO 1830

This work was funded by the Office of Technology Development, within the U.S. Department of Energy's Office of Environmental Management, under the Characterization, Monitoring, and Sensors Integrated Program

Pacific Northwest Laboratory

Richland, Washington 99352 


\section{Executive Summary}

Traditional methodologies for quantitative characterization of radionuclide-contaminated soils over extended areas are often tedious, costly, and non-representative. A rapid characterization methodology was designed that provides reliable output with spatial resolution on the order of a few meters or less. It incorporates an innovative sensor of square plastic scintillating fibers that has been designed to be placed directly on or above a contaminated soil to detect and quantify high-energy beta particles associated with the decay chains of uranium and/or strontium.

Under the direction and auspices of the DOE's Characterization, Monitoring, and Sensor Technology Integrated Program, Pacific Northwest Laboratory (PNL) constructed a high-energy beta scintillation sensor that was optimized for the detection and quantification of uranium and strontium contamination in surface soils (in the presence of potentially interfering natural and anthropogenic radionuclides), demonstrated and evaluated this detector in various field and laboratory scenarios, and provides this document in completion of the aforementioned requirements. This document summarizes the efforts by PNL during fiscal year 1994 in fulfillment of requirements set forth in TTP \#331007 (project \#19989). 


\section{Acknowledgements}

This work was prepared with the support of the following contributors:

Headquarters: $\quad$ Office of Technology Development

Characterization, Monitoring, and Sensors Integrated Program Caroline Purdy

Operations Office: $\quad$ Richland Operations Office

Technology Development Division

Deborah E. Trader, Technical Program Officer

Contractor:

Pacific Northwest Laboratory

Environmental Management Directorate

Steven C. Slate, Technical Program Manager 


\section{Contents}

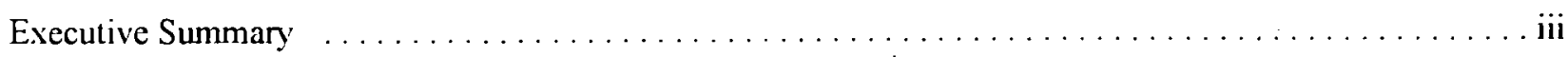

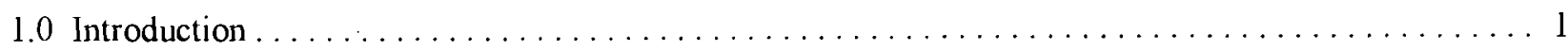

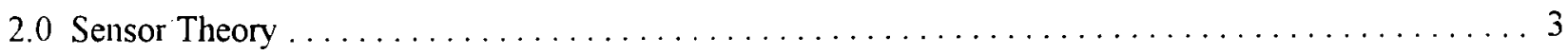

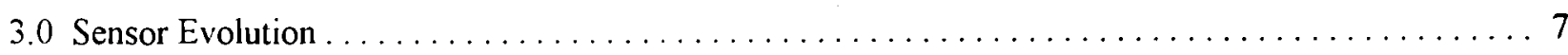

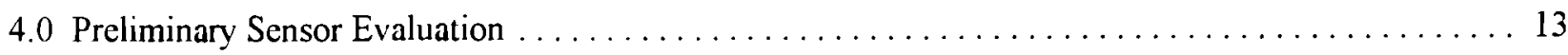

5.0 Field Demonstrations $\ldots \ldots \ldots \ldots \ldots \ldots \ldots \ldots \ldots \ldots \ldots \ldots \ldots \ldots \ldots \ldots \ldots \ldots \ldots \ldots$

5.1 Fernald Soil Decontamination Pilot Plant (SDPP) $\ldots \ldots \ldots \ldots \ldots \ldots \ldots \ldots \ldots \ldots \ldots$

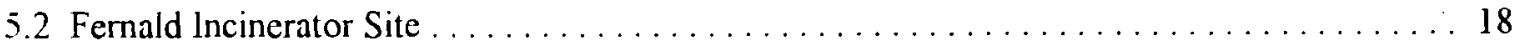



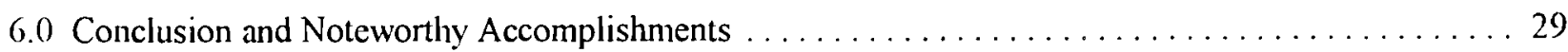

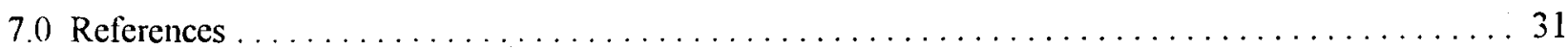




\section{Figures}

2.1. Schematic representation of the current sensor design highlighting potential interactions. Double lines denote particle tracks that lead directly to excitations/ionizations and consequent scintillations.

2.2. A plot of the projected penetration depths of various charged species in the plastic scintillant (courtesy of BICRON Corporation, Newbury, Ohio). The polynomial describing the electron/beta behavior in this material is as follows: $\log ($ range in $\mathrm{mm})=0.0419(\operatorname{logE})^{3}$ $0.172(\log \mathrm{E})^{2}+1.20(\log \mathrm{E})+0.572$

3.1. Simplified diagram of the proof-of-principle sensor showing the potential interactions between the scintillant material and incident beta particles and gamma rays. Double lines denote particle tracks that lead directly to excitations/ionizations and consequent scintillations.

3.2. Circuitry diagram for the early version of the detector identifying the actual sensor box, the supporting electronic package, and the connecting signal cable. Note the intralayer and interlayer coincidence capabilities for mitigating PMT noise and determining particle penetration depth, respectively.

3.3. Calibration plot for the proof-of-principle sensor based on a series of ${ }^{90} \mathrm{SrCl}_{2}$-spiked mediumgrained sands ( 100 -second counts). Detector response is seen to be quite linear over a significant range of activities. The non-zero count rate associated with $0 \mathrm{pCi} / \mathrm{g}$ is due to the naturally occurring uranium radioactivity in the sand samples.

3.4. Simplified circuitry diagram for the high-energy beta sensor identifying the primary signal processing stages.

4.1. Calibration plot based on ${ }^{238} \mathrm{UO}_{2}\left(\mathrm{NO}_{3}\right)_{2}$-spiked medium-grained sands. The non-zero intercept is interpreted to be a manifestation of the presence of primordial uranium activity in the surrogate soil material.

4.2. Comparative plot of net triple coincidences associated with ${ }^{90} \mathrm{Sr}$ and co-existing, potentially interfering fission products (error bars omitted for clarity). $\left({ }^{*}\right)$ denotes the beta particle energy in $\mathrm{MeV}$ (and its branching factor per 100 decays), whereas $\left({ }^{* *}\right)$ indicates the most probable penetration depth in millimeters for a normally incident particle.

5.1. Base map for the field demonstration area, situated directly north of the Fernald incinerator area. Sample sites are indicated by solid circles; southernmost row of data points (discontinuous due to the presence of the exclusion area) are equivalent to those found immediately north of the northern fenceline surrounding the incinerator site as identified in Schilk et al. 1993a. Approximatc location of the actual incinerator stack: easting $=+50$ feet, northing $=.50$ feet. 
5.2. Combined results of two separate calibrations (indicated by upward- and downward-pointing triangles) performed on separate days at the Fernald incinerator site. Standards were composed of spiked local soils. The calibration curve is well behaved, with a linear slope and a near-zero intercept.

5.3. Uranium activity as a function of time at standard plot \# 1 (beginning at 0905) and following a period of heavy rain. See text for explanation.

5.4. Uranium surface-activity contour map based on a geostatistical analysis of the beta sensor measurements. As predicted, the surface activity is greatest near the exclusion zone (directly downwind of the incinerator stack) and decreases in a north-northeasterly direction.

5.5. Uranium surface-activity contour map based on a geostatistical analysis of the in situ gamma-ray spectrometer measurements. Qualitatively, these results are consistent with Figure 6.1. See text for explanation of quantitative differences.

5.6. Uranium surface-activity contour map based on a geostatistical analysis of the hand sample/ laboratory analysis measurements. Qualitatively, these results are consistent with Figure 6.I. See text for explanation of quantitative differences.

5.7. Correlation plot comparing the in situ gamma-ray measurements and the beta sensor response. The correlation coefficient $(r)$ is significant, indicating that the results are mutually supportive. . . 26

5.8. Correlation plot comparing the hand sample analyses and the beta sensor response. The correlation coefficient ( $r$ ) is significant, indicating that the results are mutually supportive. 



\subsection{Introduction}

At least 59 individual waste sites at 14 U.S. Department of Energy (DOE) facilities across the nation have been identified as exhibiting radioactive contamination in excess of established limits (Riley and Zachara 1992). In many cases, the radionuclides of concen include ${ }^{238} \mathrm{U}$ and ${ }^{90} \mathrm{Sr}$. The need to rapidly and efficiently characterize these sites and the potentially contaminated regions that surround them (a combined area of hundreds of square miles) represents a technological challenge with no existing solution.

Traditional methodologies for quantitative characterization of radionuclide-contaminated soils over cxtended areas are often tedious, costly, and non-representative. Such means include ground-deployable gamma-ray-measurement techniques (e.g., in situ gamma-ray spectrometry) and aerial surveys using $\mathrm{NaI}(\mathrm{Tl})$ or HPGe gamma-ray sensors for uranium detection, and hand sampling followed by gamma-ray counting (for uranium) or extensive radiochemistry and subsequent beta-particle counting (for both strontium and uranium).

A rapid (i.e., real-time) characterization methodology was designed that provides reliable output with spatial resolution on the order of a few meters or less. It incorporates an innovative sensor of square plastic scintillating fibers that has been designed to be placed directly on or above a contaminated soil to detect and quantify high-energy beta particles associated with the decay chains of uranium and/or strontium. 


.




\subsection{Sensor Theory}

The sensor (Figure 2.1) employs a vertically stacked configuration of fiber ribbons that enables the determination of the penetration depths of incident charged particles and allows differentiation between (a) unattenuated betas from ${ }^{90} \mathrm{Y}$ or ${ }^{234 \mathrm{~m}} \mathrm{~Pa}$ (decay daughters of ${ }^{90} \mathrm{Sr}$ and ${ }^{238} \mathrm{U}$, respectively) and (b) lower-energy beta particles arising typically from natural sources (namely, other ${ }^{238} \mathrm{U}$ daughters, ${ }^{232} \mathrm{Th}$ and its daughters, and ${ }^{40} \mathrm{~K}$ ). Strictly speaking, this sensor indirectly detects uranium and strontium activity based on the assumption that secular equilibrium exists between the parent radionuclide and its daughter, as follows:

${ }^{238} \mathrm{U}(4.47 \mathrm{E} 9 \mathrm{a})-->{ }^{234} \mathrm{Th}(24.1 \mathrm{~d})-->{ }^{234 \mathrm{~m}} \mathrm{~Pa}(1.17 \mathrm{~m}) \ldots-$--> ${ }^{206} \mathrm{~Pb}$ (stable)

${ }^{90} \mathrm{Sr}(29.1 \mathrm{a})-{ }^{9}{ }^{90} \mathrm{Y}(2.67 \mathrm{~d})-->{ }^{90} \mathrm{Zr}$ (stable)

In the case of strontium-yttrium, this would occur within 3 weeks of production of the strontium parent (or any fractionation process in which parent and daughter were separated). Such a condition would not occur for 5 or 6 months for the uranium-protactinium case, due to the relatively long-lived intermediary, ${ }^{234} \mathrm{Th}$. With regard to contaminated soils at existing DOE facilities, the assumption of secular equilibrium is valid in most, if not all, cases, and the detected activity of the daughter is essentially equivalent to that of the parent isotope. For new or recently fractionated material, however, potential disequilibria should be carefully evaluated when using this technology.

Yttrium-90 and ${ }^{234 \mathrm{~m}} \mathrm{~Pa}$ eacl decay by emitting a $2.3-\mathrm{MeV}$ maximum-energy beta particle $(100 \%$ and $98 \%$ branching ratios, respectively $)^{\prime}$. When traveling normally incident to the sensor face and at their most probable energy (approximately $800 \mathrm{keV}$ ), these betas would be expected to penetrate roughly $3 \mathrm{~mm}$ of plastic scintillator (Figure 2.2). This phenomenon would be manifested by virtually simultaneous light output in each of the three lower layers. Conversely, the most probable beta energies from the naturally occurring radionuclides (see above) rarely exceed $350 \mathrm{keV}$, or the associated abundances of such particles are relatively insignificant compared with unattenuated betas from ${ }^{90} \mathrm{Y}$ or ${ }^{234 \mathrm{~m}} \mathrm{~Pa}$. Hence, the likely penetration depth of an unattenuated, normally incident "background" beta will generally be $\leq 1 \mathrm{~mm}$, making it readily distinguishable from the radionuclides of interest.

Gamma rays originating from the soil and surrounding materials and cosmic-induced species (protons, muons, etc.) are ubiquitous phenomena responsible for a majority of the background signal associated with the sensor. A charged particle will cause continuous excitations and consequent scintillation events along its entire path through the scintillator stack, while a gamma ray might produce a Compton electron in only one (indeed, if any) of the individual layers of the low- $Z$ detector material (the photoelectric effect is virtually non-existent in solid hydrocarbons). False- positive signals due to gamma-ray interactions, such as the concurrent generation of Compton electrons in all three layers by one or more incident photons, or the production of a particularly energetic electron in the first layer that subsequently traverses the second and

'It should be noted that this sensor cannot distinguish between the $2.29-\mathrm{MeV}$ beta from ${ }^{234 n} \mathrm{~Pa}$ and the $2.28-\mathrm{MeV}$ beta from ${ }^{90} \mathrm{Y}$. The sensor responses associated with these radionuclides are virtually identical. 


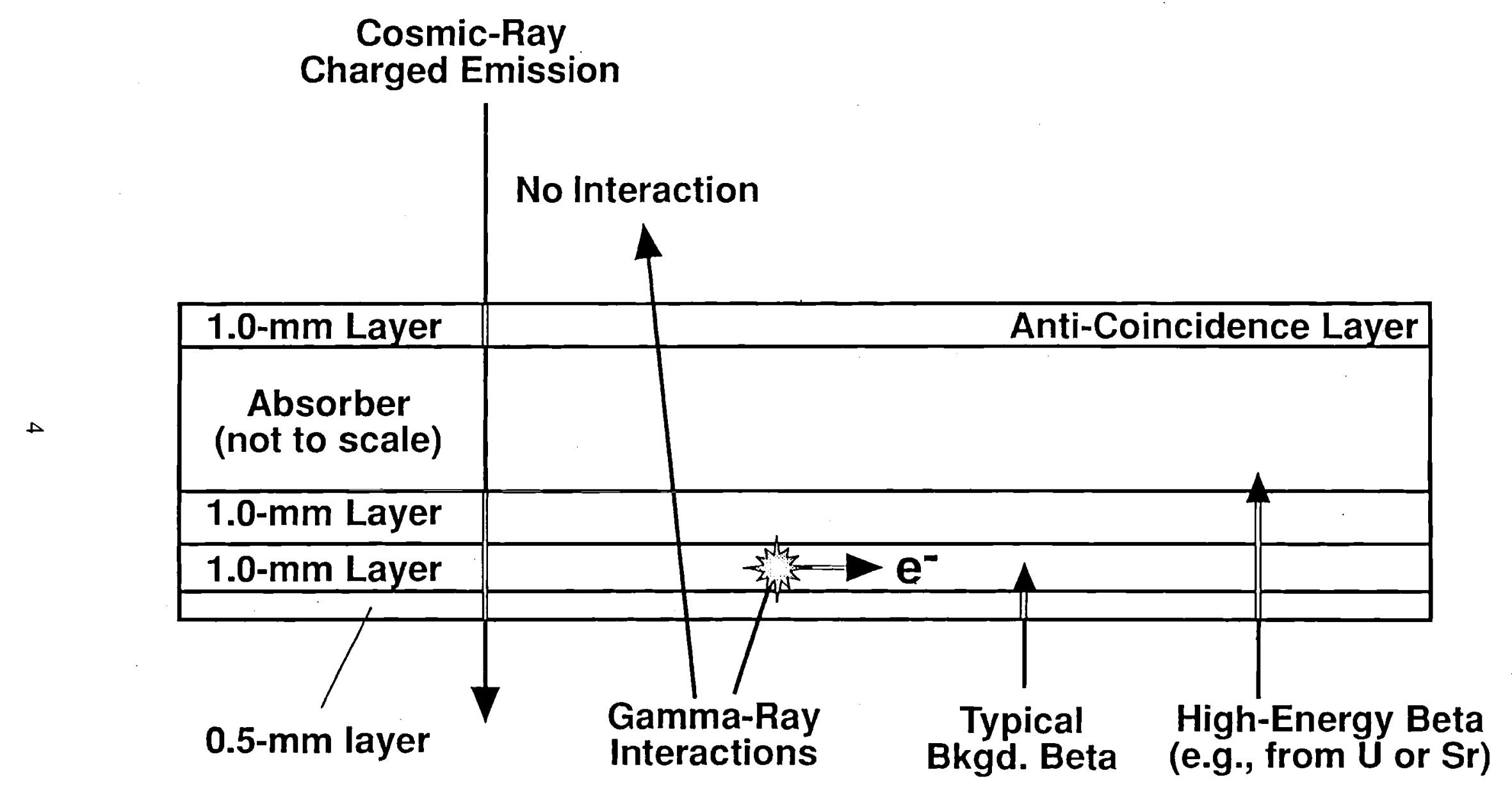

Figure 2.1. Schematic representation of the current sensor design highlighting potential interactions. Double lines denote particle tracks that lead directly to excitations/ionizations and consequent scintillations. 


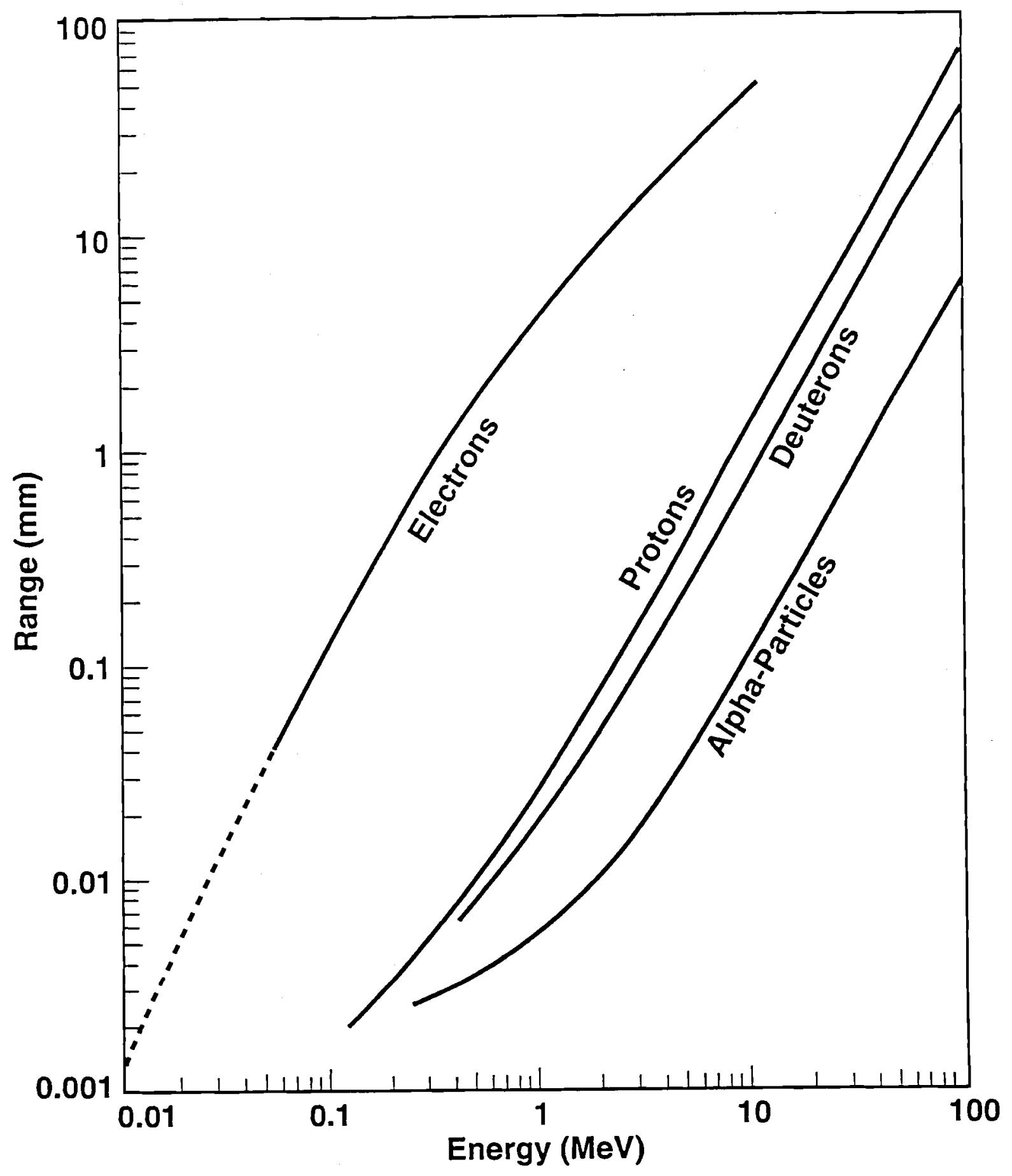

39406099.1

Figure 2.2. A plot of the projected penetration depths of various charged species in the plastic scintillant (courtesy of BICRON Corporation, Newbury, Ohio). The polynomial describing the electron/beta behavior in this material is as follows: $\log ($ range in $\mathrm{mm})=0.0419(\operatorname{logE})^{3}$ $0.172(\log E)^{2}+1.20(\log E)+0.572$ 
third layers, are rare but not improbable and are decreased through the use of a $0.5-\mathrm{mm}$ layer in front of the stack. This approximately halves the number of gamma-induced scintillations in the first layer, decreasing the total number of false positives proportionately. A $0.25-\mathrm{mm}$-thick layer was also investigated for gammaray discrimination and the resulting gamma background was further reduced; however, the loss in beta cfficiency associated with the thinner material was greater than its overall signal-to-noise-enhancement.

Detector background is also decreased by placing an anti-coincidence shield above the active detector volume (Figure 2.1). Cosmic-induced events, caused by charged species that originate above the sensor and penetrate the overlying anti-coincidence fiber ribbon as well as the three lower layers (a quadruple coincidence), lead to signals that are ultimately rejected by the sensor electronics. An acrylic absorber between the triple stack and the anti-coincidence layer ensures that no betas of interest originating from the underlying source can reach the uppermost ribbon and be discarded. 


\subsection{Sensor Evolution}

A schematic of the proof-of-principle detector is shown in Figure 3.1. For this sensor, a number of square, 1-mm-thick scintillating fibers were fashioned into three flat ribbons ( $150 \mathrm{~mm}$ wide by approximately $100 \mathrm{~cm}$ long), each end of which was bundled, milled flat, and placed in optical contact with a 19-mm lownoise, high-gain photomultiplier tube (PMT). These commercially available fibers are polystyrene-based with polymethylmethacrylate cladding, and are doped with various fluorescent compounds that produce the desired scintillation, optical, and radiation-resistant characteristics. The PMT signal outputs were amplified and passed by a 3-meter cable to an electronic package containing secondary amplifiers, signal discriminators, and custom logic circuitry. The resulting data (e.g., total counts in individual layers and interlayer coincidences) were displayed on counters and relayed to a personal computer for storage (see Figure 3.2).

The proof-of-principle sensor performed well in laboratory trials with spiked soil standards (Figure 3.5). Furthermore, it was successfully used to map contamination levels in surface soils and assist in establishing remedial protocols at a defunct uranium processing facility (see Schilk et al. 1993b; Schilk et al. 1994). The minimum detectable activity for ${ }^{238} \mathrm{U}$, around $10-15 \mathrm{pCi} / \mathrm{g}$, was limited by the high baseline signal (approximately 17 counts per second in the triple-coincidence mode) and was primarily a function of uncompensated background influences.

The current sensor design (see Figure 2.1), developed in fiscal year 1994 under the auspices of the Characterization, Monitoring, and Sensor Technology Integrated Program, has a larger active region than the previous version (measuring $30 \mathrm{~cm}$ by $60 \mathrm{~cm}$ ), and incorporates improvements that decrease the inherent background signal observed in the proof-of-principle detector. The result is an enhanced overall signal-tonoise ratio. Cosmic influences are minimized by incorporating an overlying anti-coincidence ribbon that detects energetic charged particles originating above the sensor and rejects them. A 6-mm-thick acrylic absorber separates the cosmic anti-coincidence ribbon from the lower layers and prevents any betas from the soil from triggering the anti-coincidence circuitry. Gamma-ray-induced triple coincidences are reduced by placing a thinner scintillating fibers in the laver closest to the soil, which decreases the probability of generating Compton electrons in this layer. In addition, significant improvements to the electronic components and circuitry allowed the establishment of a much narrower coincidence window (on the order of 10-20 ns), further decreasing the background generated by coincident thermionic emissions from multiple PMTs. This combination has led to a mucl lower background count rate (less than 6 counts per second) despite the fact that the existing sensor has a larger sensitive region than the earlier version $\left(2700 \mathrm{~cm}^{3}\right.$ versus $\left.1500 \mathrm{~cm}^{3}\right)$.

Figure 3.4 is a simplified schematic of the supporting electronics, which were designed specifically for this application. The need for high sensor efficiency coupled with an extremely low background signal led to a novel design approach that uses high-speed processing electronics to maintain the integrity of the PMT outputs. The current pulses from each PMT are amplified by a two-stage microwave amplifier circuit (>2$\mathrm{GHz}$ bandwidth) and converted to high-fidelity voltage pulses. The integration time of the amplifier is chosen to be equivalent to the collection time of the current pulse, which leads to the production of highamplitude $(>100 \mathrm{mV})$, narrow ( $<10 \mathrm{~ns}$ FWHM) voltage pulses for single-photon events. 


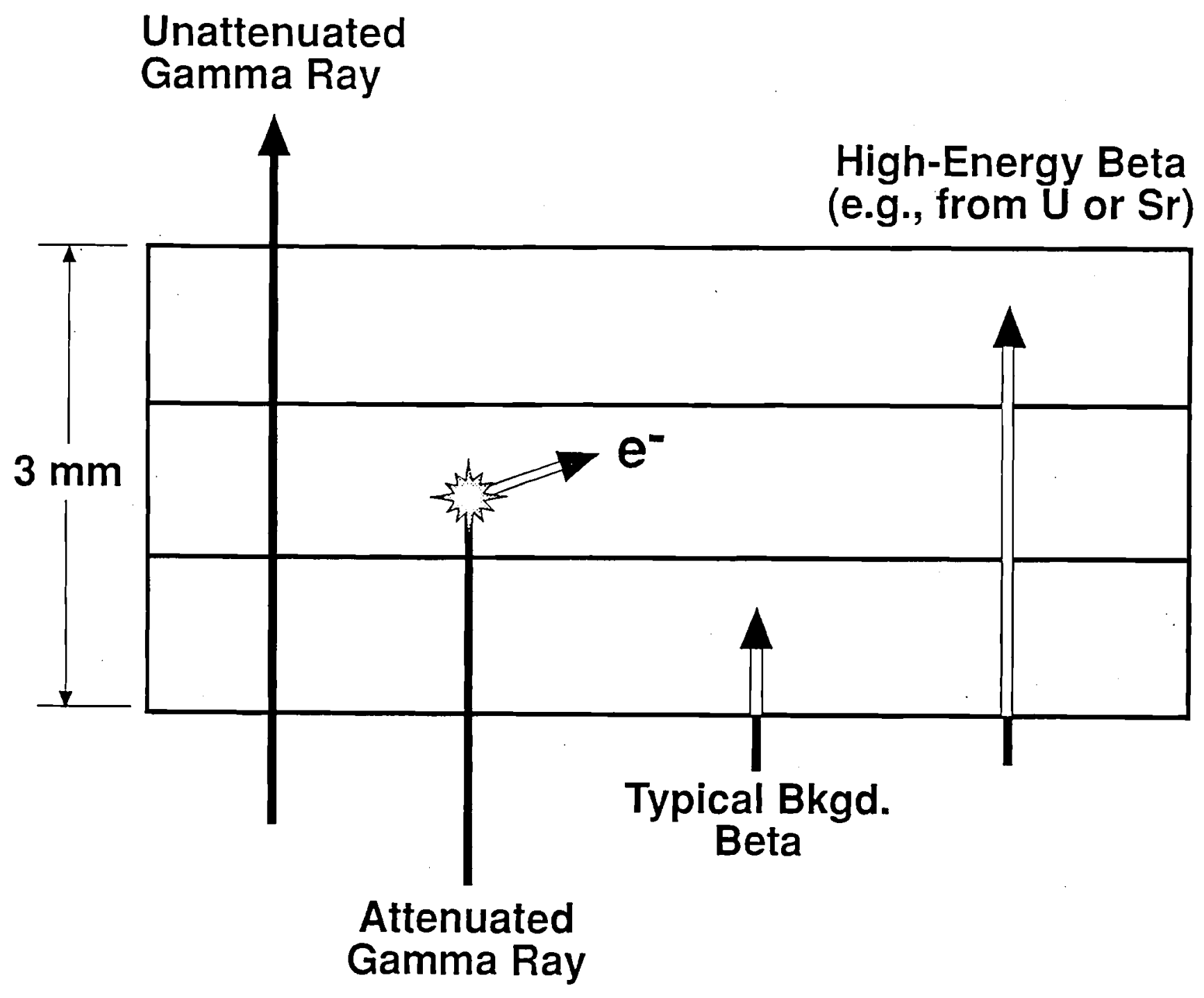

Figure 3.1. Simplified diagram of the proof-of-principle sensor showing the potential interactions between the scintillant material and incident beta particles and gamma rays. Double lines denote particle tracks that lead directly to excitations/ionizations and consequent scintillations. 


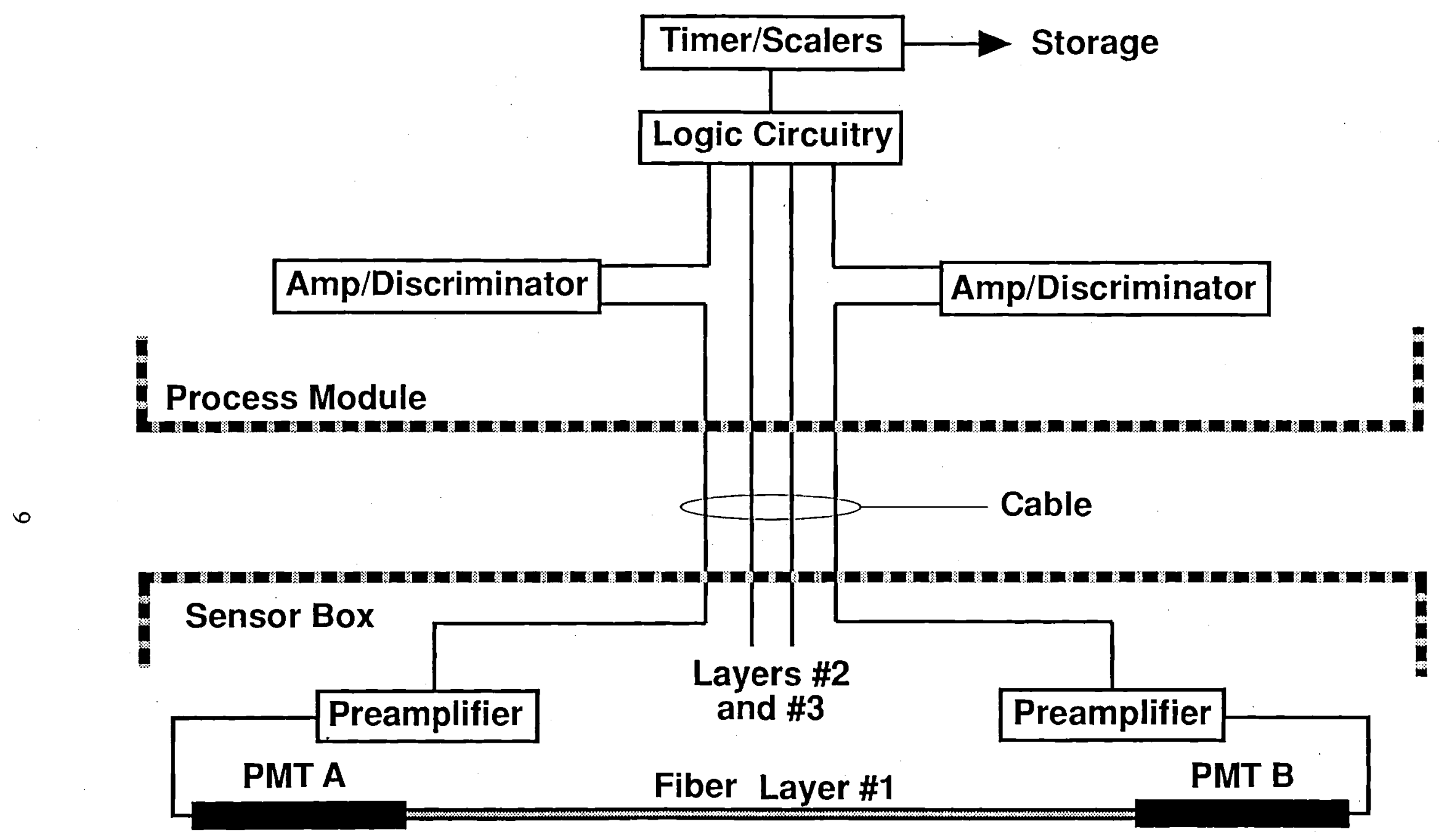

39403052.3

Figure 3.2. Circuitry diagram for the early version of the detector identifying the actual sensor box, the supporting electronic package, and the connecting signal cable. Note the intralayer and interlayer coincidence capabilities for mitigating PMT noise and determining particle penetration depth, respectively. 


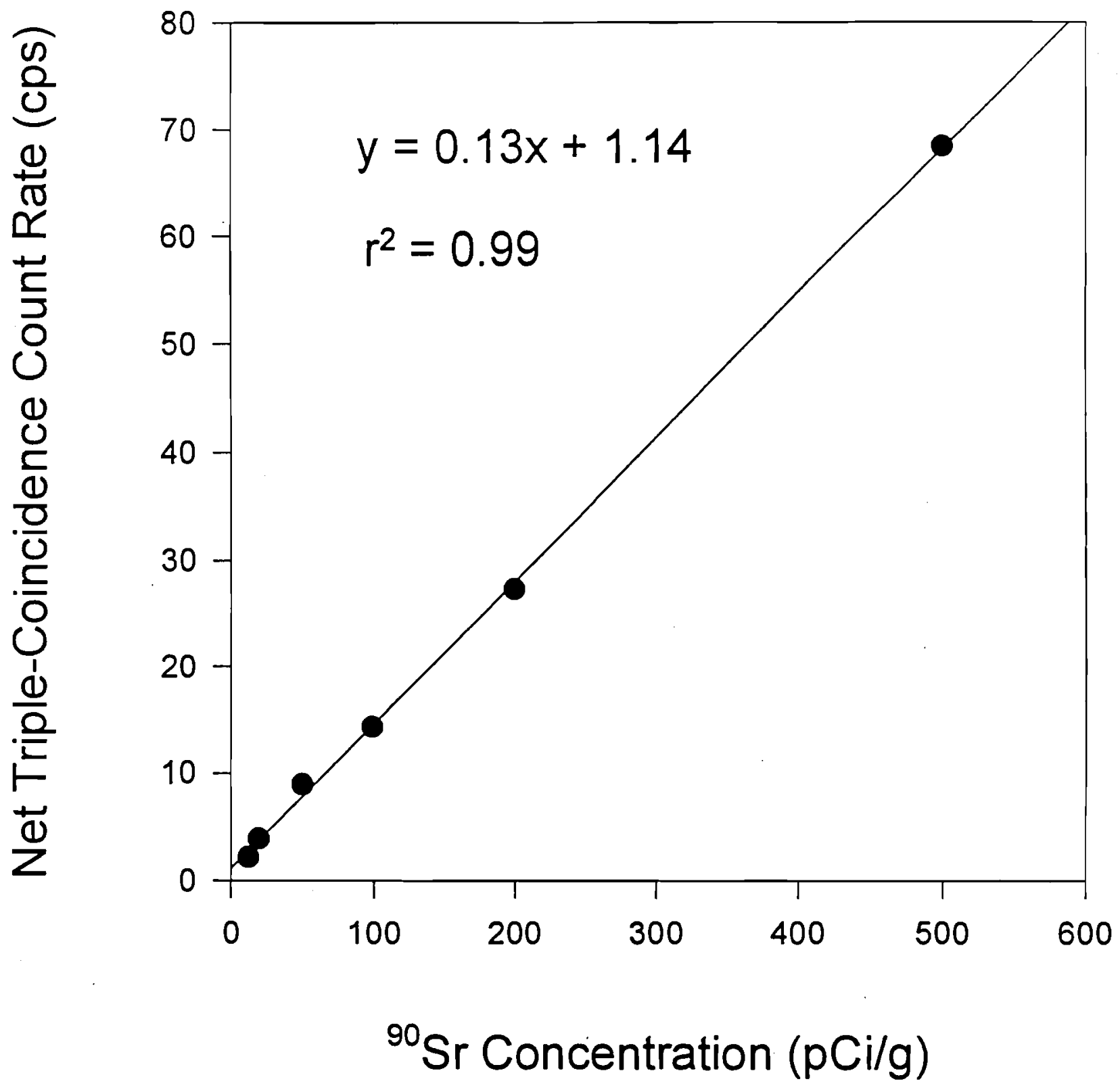

Figure 3.3. Calibration plot for the proof-of-principle sensor based on a series of ${ }^{90} \mathrm{SrCl}_{2}$-spiked medium-grained sands (100-second counts). Detector response is seen to be quite linear over a significant range of activities. The non-zero count rate associated with $0 \mathrm{pCi} / \mathrm{g}$ is due to the naturally occurring uranium radioactivity in the sand samples. 


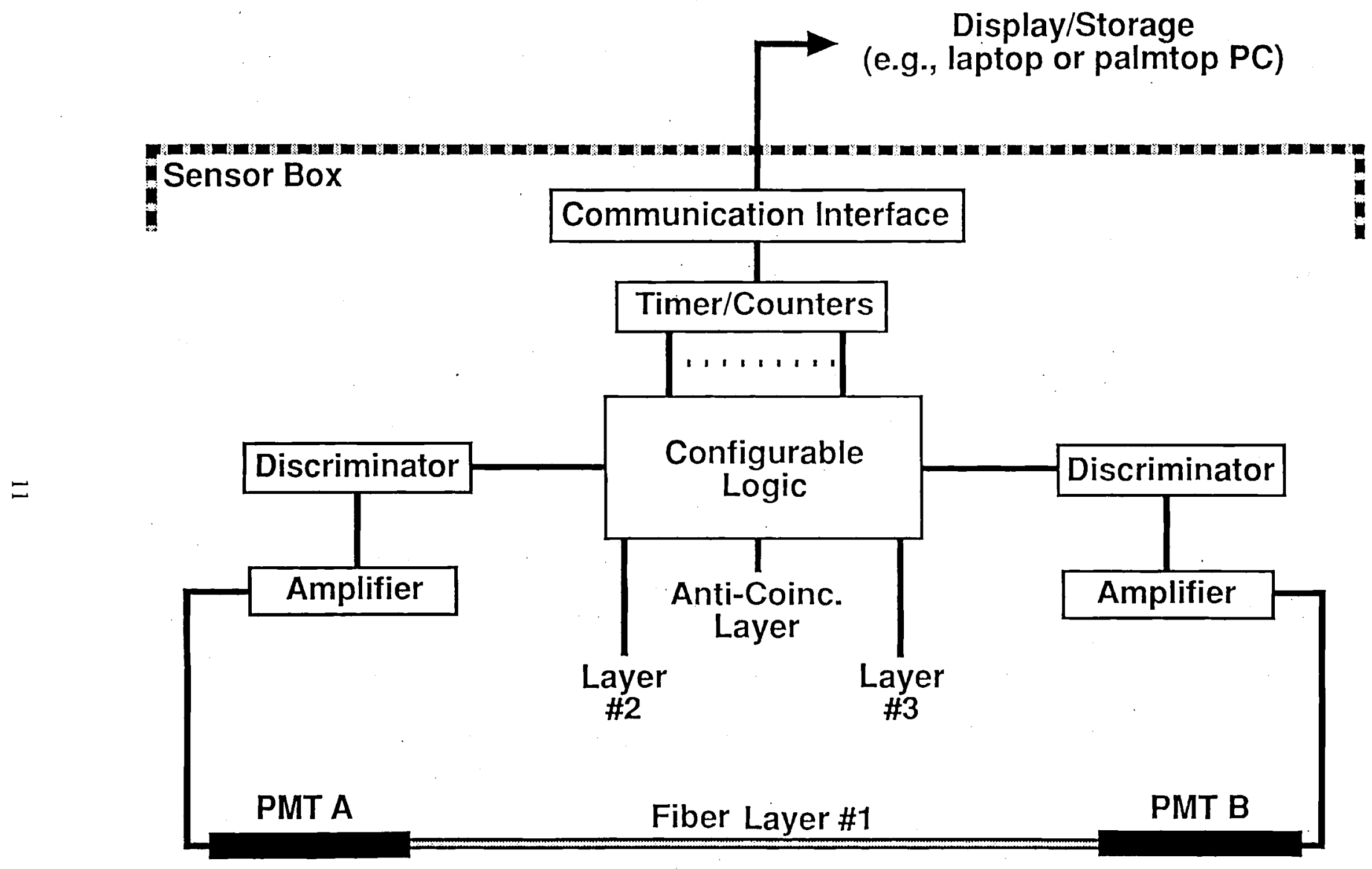

39403052.4

Figure 3.4. Simplified circuitry diagram for the high-energy beta sensor identifying the primary signal processing stages. 
To allow differentiation between valid signal pulses and noise generated in the PMT or amplification circuitry, a lower-level discriminator was placed at the amplifier output. This discriminator includes an analog-level comparator with high-speed emitter-coupled-logic (ECL) outputs. The comparator reference can be set well below the single-photon peak, yet still appreciably above the noise signal. This results in a significantly enhanced signal-to-noise ratio. The comparator also allows for adjustment of the output pulse width (nominally, from 8 to $50 \mathrm{~ns}$ ) that, in turn, controls the time window associated with interlayer and intralayer coincidence overlaps. The end-to-end, or intralayer, coincidence requirement mitigates against false positives generated by thermionic emissions from the individual PMTs, while the interlayer coincidences are a direct indication of charged-particle penetration depths.

Both types of coincidences are interrogated by an ECL programmable logic device that provides input to a data-acquisition system consisting of a counter/timer board and an embedded 386 processor (both are in PC-104 format). The counter/timer board incorporates a number of 16-bit counter/timers, six of which receive input from the sensor's logic circuitry and are used to count the number of event pulses that occur during a user-determined count interval. This interval is generated by a separate counter that is connected to an on-board oscillator and configured as a repetitive countdown timer. By varying the reload value for the countdown timer, the user can change the duration of the count interval from 0.1 to 65.5 seconds. At the end of cach counting interval, this timer generates a pulse that is used to latch the values of the event counters (causing them to reset and allowing the initiation of a new counting interval) and sends an interrupt to the processor. The processor performs all acquisition, control, and diagnostic functions and allows direct communication with an external computer via an RS-232 serial port.

The data acquisition and control software was written in $C$ language, although some inline assembly code was included where speed was a critical issue. The program revolves around two interrupt service routines (ISRs) that store incoming characters from the serial port and read event counts as they become available. The main program is a continuous loop that waits for new-event count data or new serial commands. As new count sets become available, the main program formats them into a comma-delimited ASCII string that is sent out the serial port.

The serial port is configured for 9600 baud, no parity, 8 data bits,and 1 stop bit. Serial I/O is handled by an ISR that stores new characters received on the RS-232 in a ring buffer. A set of support functions is used to read characters from the ring buffer or to send characters via the serial port. Commands and data are made up of printable ASCII characters that are sent as strings terminated with a hard return. An ASCll format was chosen for communications instead of a binary format for two reasons. First, by using all ASCII characters, the detector can be controlled by any ASCII terminal or terminal emulator. Secondly, convenient error recovery is achieved by using the hard return at the end of each command as a resynchronization character.

A simple utility program has been written to control specific sensor features (count interval duration, PMT bias supply, etc.) and is designed to be run on a palmtop, laptop, or other portable computer. Data transmitted from the detector are displayed on screen and can be logged to file for later analysis. 


\subsection{Preliminary Sensor Evaluation}

Following sensor construction, a series of surrogate soils were prepared (using appropriate radioisotopic solutions and a local, medium-grained river sand of basaltic origin) to evaluate the system response to various contaminants. The homogeneously spiked sands were placed in plastic trays measuring $65 \mathrm{~cm}$ by $35 \mathrm{~cm}$ by $2 \mathrm{~cm}(5 \mathrm{~cm}$ longer and wider than the sensor's active area, and a depth that represents an infinite soil thickness with respect to the beta particles in question), and covered by a thin plastic sheet to preclude the inadvertent transfer of radioactive material. All standards were centered beneath the sensor at a consistent distance of 1 to 2 centimeters, and background measurements were initiated before and after each series of counts to monitor sensor stability. A calibration plot for three ${ }^{238} \mathrm{UO}_{2}\left(\mathrm{NO}_{3}\right)_{2}$-spiked sands is shown in Figure 4.1, which indicates that the sensor response is linear in the region of low specific activity. Count times for this test ranged from 2 minutes (standard soils) to 10 minutes (background), and associated errors, although relatively large, are essentially equivalent to those expected for a Poisson distribution.

Next, an attempt was made to determine the effects of co-existing radionuclides on strontium detection in soils. The choice of potentially interfering species was based on computer-generated concentrations of fission products that are expected to be present in soils contaminated with Hanford reactor fuel after 10 to 40 years of decay (Perkins and Jenquin 1994). To this end, a series of standards were prepared (as above) that contained roughly equal concentrations of ${ }^{90} \mathrm{SrCl}_{2},{ }^{137} \mathrm{CsCl},{ }^{147} \mathrm{PmCl}_{3},{ }^{154} \mathrm{EuCl}_{3}$, and ${ }^{155} \mathrm{EuCl}_{3}$. These surrogate soils were counted for one hour, corrected for background, and normalized to the ${ }^{90} \mathrm{Sr}$ response.

It can be seen (Figure 4.2) that the sensor design is particularly insensitive to the low-energy beta particles associated with ${ }^{147} \mathrm{Pm}$ and ${ }^{155} \mathrm{Eu}$, even when these radionuclides exist at activity levels that are comparable to that of ${ }^{90} \mathrm{Sr}$. In fact, the relative percentages of these isotopes are orders of magnitude lower than the strontium content in reactor-fuel-contaminated soils $(0.077 \%$ and $0.022 \%$ versus $22.73 \%$, respectively, in 30-year-old fuel [ibid.]), further mitigating against their effects in an actual environmental scenario. Cesium-137 and ${ }^{90} \mathrm{Sr}$ levels, on the other hand, are predicted to be subequal [ibid.], and this evaluation shows that under such conditions, the sensor is effective in ignoring the contribution from this coexisting contaminant.

Conversely, ${ }^{154}$ Eu leads to a substantial triple-coincidence response in the current sensor design. This is not surprising when one considers that any beta particle exceeding approximately $1.5 \mathrm{MeV}$ (maximum energy) would be expected to penetrate the third layer of the existing sensor and generate a viable signal, and ${ }^{154} \mathrm{Eu}$ has an associated $1.86-\mathrm{MeV}$ beta ( $12 \%$ abundance) that is capable of traversing over $2 \mathrm{~mm}$ of plastic (see Figure 2). This issue could be resolved by adding a third $1-\mathrm{mm}$ layer to the lower portion of the sensor stack, thereby precluding any but the $2.28-\mathrm{MeV}^{90} \mathrm{Y}$ beta from reaching the final ribbon. This would appear to be unnecessary, however, as the actual ${ }^{154} \mathrm{Eu} /{ }^{\rho 0} \mathrm{Sr}$ ratios in reactor-fuel-contaminated soils are predicted to be quite low $(<1 \%$ after 10 years [ibid.]), and the relative contribution from this isotope is largely insignificant. 


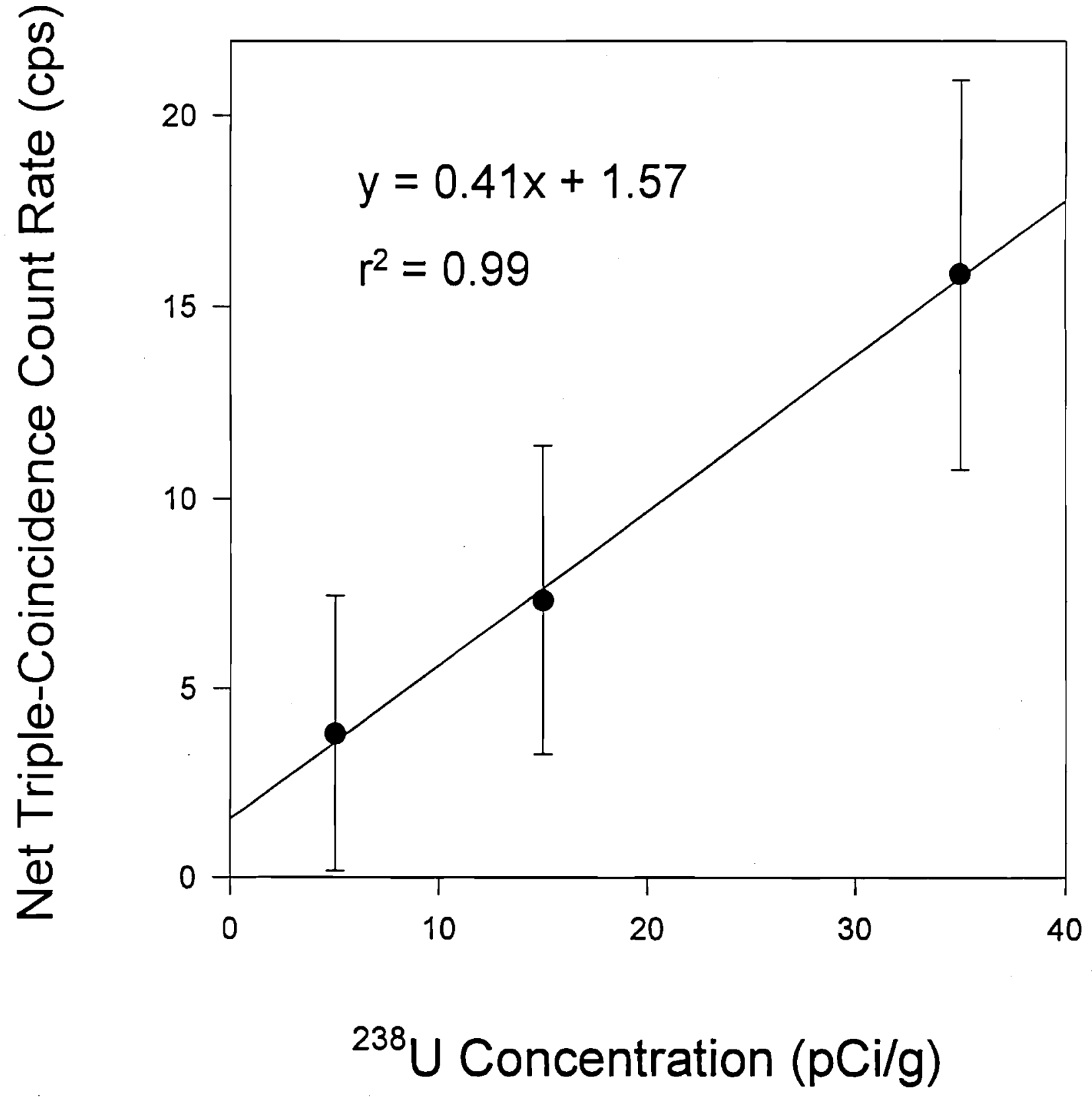

Figure 4.1. Calibration plot based on ${ }^{238} \mathrm{UO}_{2}\left(\mathrm{NO}_{3}\right)_{2}$-spiked medium-grained sands. The non-zero intercept is interpreted to be a manifestation of the presence of primordial uranium activity in the surrogate soil material. 


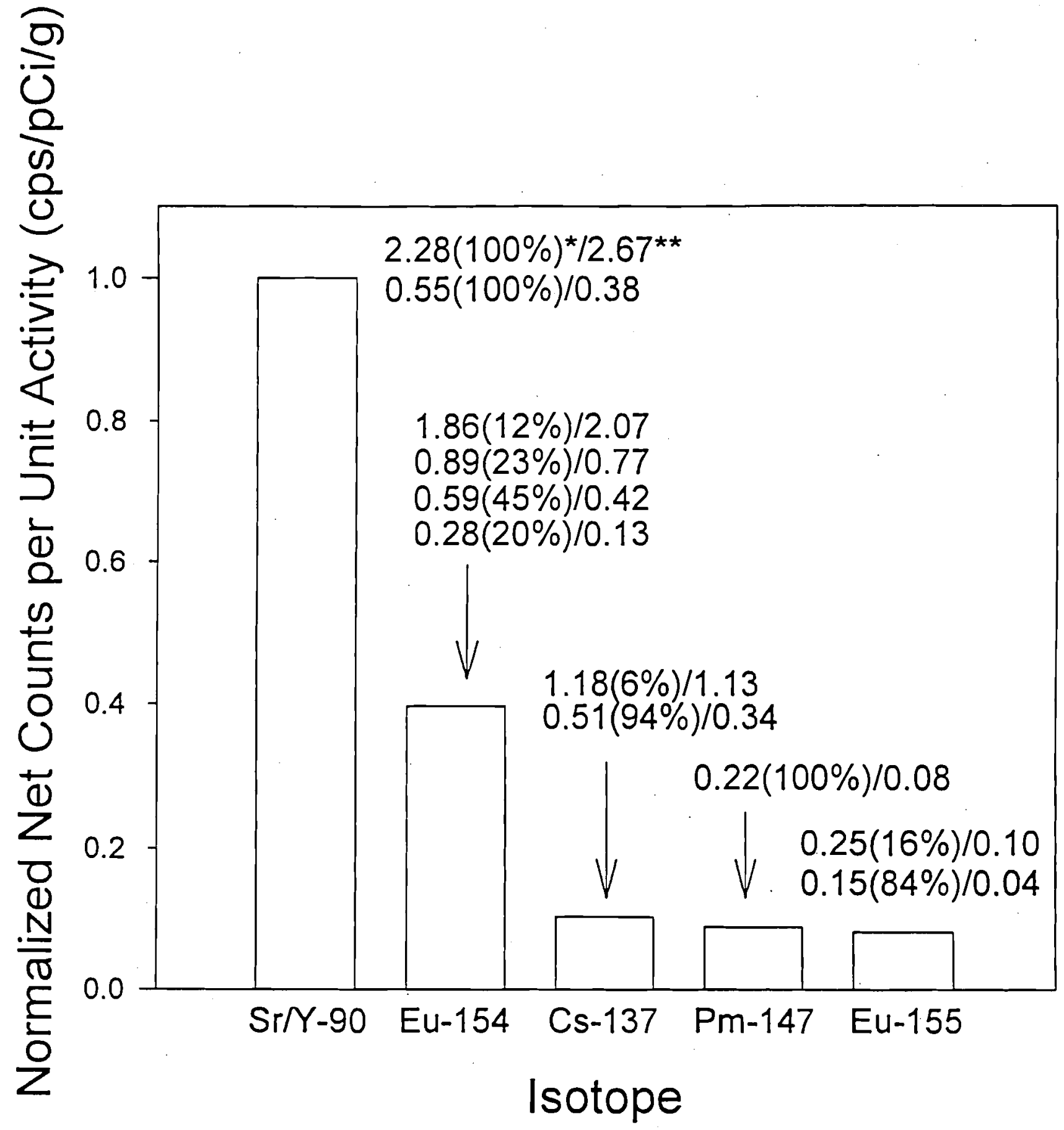

Figure 4.2. Comparative plot of net triple coincidences associated with ${ }^{90} \mathrm{Sr}$ and co-existing, potentially interfering fission products (error bars omitted for clarity). (*) denotes the beta particle energy in $\mathrm{MeV}$ (and its branching factor per 100 decays), whereas $\left({ }^{* *}\right)$ indicates the most probable penetration depth in millimeters for a normally incident particle. 


\subsection{Field Demonstrations}

\subsection{Fernald Soil Decontamination Pilot Plant (SDPP)}

The beta scintillation sensor was evaluated (Schilk and Knopf 1994) at Fernald's SDPP to establish the utility of such a detector for the measurement of uranium-contaminated soils from various stages of a soilwashing process stream in a relative-motion (i.e., conveyor-belt) scenario. The intent of this test was to investigate the efficiency, sensitivity, accuracy, reliability, reproducibility, and system constraints associated with the sensor in terms of the quantification of uranium content in a moving soil sample.

With regard to contaminated soils associated with existing DOE facilities, the assumption of secular equilibrium is valid in most, if not all, cases, and the detected activity of the daughter (e.g., ${ }^{234} \mathrm{Th}$ and $\left.{ }^{234 \mathrm{ma}} \mathrm{Pa}\right)$ is essentially equivalent to that of the parent isotope $\left({ }^{238} \mathrm{U}\right.$ ). For new or recently fractionated material (as in the case at the SDPP), however, one must be cognizant of potential disequilibria when using this methodology. Measuring uranium indirectly does not preclude effective use of the beta sensor for such a scenario, but necessitates a thorough understanding of the ${ }^{238} \mathrm{U}_{-}{ }^{234} \mathrm{Th}^{2}$ decontamination ratios (i.e., the degree of uranium and thorium stripping as a function of the washing process). After these ratios have been accurately determined via an appropriate method (note that these parameters would be constant for a continuous-mode process with consistent resident times and reagent concentrations), they need only be incorporated into the sensor's data-reduction program to compensate for any uranium-protactinium (or uranium-thorium) disequilibria. Alternatively, if the ${ }^{234} \mathrm{Th}$ concentration in the soil is entirely unaffected by the decontamination process while a fraction of the uranium is removed, then it would not be possible to correlate the beta sensor response to ${ }^{238} \mathrm{U}$ content.

The temporal relationship between the U-(Th?-)removal stage and the monitoring phase is also significant. Normally, the latter would immediately follow the former in a continuous-mode process, but if a significant delay occurs between soil stripping and effluent counting phases (e.g., on the order of weeks, as was the case in this evaluation), additional corrections are necessary to compensate for the decay of remnant 24. $1-\mathrm{d}^{234} \mathrm{Th}$. This can be readily compensated for in the data-reduction process.

A number of background counts were initiated at the SDPP to determine the inherent stability of the scnsor. One-hour counts were taken at various times during the evaluation process while the sensor was maintained in a standardized configuration ( 1 to $2 \mathrm{~cm}$ above the sample surface and centered on the conveyorbelt width). The average background count rate within the SDPP facility was found to be comparable to that observed under previous laboratory conditions, with a net triple-coincidence rate of approximately 7 counts per second.

Three medium-grained sand samples were spiked with a solution of ${ }^{238} \mathrm{UO}_{2}\left(\mathrm{NO}_{3}\right)_{2}$ to levels of 5,15 , and $35 \mathrm{pCi}$ of ${ }^{238} \mathrm{U}\left({ }^{234} \mathrm{Th},{ }^{234 \mathrm{~m}} \mathrm{~Pa}\right.$ ) per gram to facilitate the sensor calibration. These sources were first characterized in the laboratory (see Figure 5.1) and an additional calibration was performed at the SDPP, although in this case the width of the soil standard was restricted to $20 \mathrm{~cm}$ to match the conveyor-belt

\footnotetext{
2It should be noted that the ${ }^{234 \mathrm{~m}} \mathrm{~Pa}$ activity level becomes essentially equivalent to that of ${ }^{234} \mathrm{Th}$ within 10 minutes.
} 
dimensions. Nonetheless, the SDPP calibration corroborated the laboratory data, in that the plot intercepts were essentially equivalent and the regression slopes differed by a constant factor that was a direct function of the actual surface areas of the standards. Specifically, the slope of the SDPP calibration plot was $63 \%$ of that associated with the laboratory plot $(0.26$ versus 0.41$)$, while the active soil area for the SDPP runs was roughly two-thirds, or $67 \%$, of the laboratory standards.

Static runs were performed on damp effluent soils from the SDPP to determine the extent of any residual activity following the decontamination process. All samples were arranged in the same geometry as the aforementioned standards and were counted for 30 minutes each. Based on the above calibration, soils were found to contain residual activity in excess of $100 \mathrm{pCi} / \mathrm{g}$ of ${ }^{234} \mathrm{Th}-{ }^{234} \mathrm{maa}\left({ }^{238} \mathrm{U}\right.$ ?). Some concern existed with regard to the moisture content of these soils and the potential effects of interstitial water on the sensor response. This excessive moisture (approx. $50 \mathrm{wt} \%$ water) was expected to act as an additional beta attenuator and lead to results that were erroneously low. A duplicate soil aliquot was collected and heated overnight in an oven to eliminate all adsorbed water in the sample. The sample was crushed to create irregular fragments ranging from fine dust to approximately 6 millimeters. The dried soil was counted for 30 minutes and the total activity was determined to be roughly double that observed for the damp aliquot. Moisture content is a critical parameter and must be well characterized before this sensor is used to quantify radionuclide activities.

The effectiveness of the sensor for analyzing soils on a moving belt was evaluated. This is a realistic operational scenario with respect to the projected continuous-mode decontamination facility at the SDPP. In this investigation, the sand standards were passed 1 to $2 \mathrm{~cm}$ below the sensor at various belt speeds (approximately 1,5 , and 15 feet per minute) to establish dynamic calibrations as a function of relative speed. These calibrations were based on the nel cumulative counts obtained during each traverse of a 20 -cm by 60 $\mathrm{cm}$ by $1-\mathrm{cm}$ soil standard, from the time at which the standard's leading edge reached the sensitive area of the sensor to the point when the standard's trailing edge left this region. Damp soil samples were then monitored under equivalent conditions, and net counts were determined as above. The resulting data indicated that the sensor response was quite consistent for multiple belt speeds (ibid.), and that static and dynamic results were mutually supportive.

At this point, and before any radiological assays to determine the extent of potential ${ }^{238} \mathrm{U}^{234} \mathrm{Th}$ ( $\left.{ }^{234 m} \mathrm{~Pa}\right)$ disequilibria created by the soil-washing process, it would be imprudent to claim that the dry-sample results obtained from this evaluation are equivalent to effluent uranium concentrations. These results, however, are certainly indicative of the ${ }^{234} \mathrm{Th}$ content in the samples and, as mentioned previously, can be converted to ${ }^{238} \mathrm{U}$ activity levels if (a) specific conditions exist (e.g., uranium and thorium must both be affected to some degree by the physical/chemical stripping process) and (b) information regarding the uranium-thorium decontamination ratio (normally, a constant parameter) is available. Hence, the incorporation of such a sensor into a soil-washing process stream (following a suitable calibration that addresses the issues described above) may enhance the rapid and efficient decontamination of target soils

\subsection{Fernald Incinerator Site}

During fiscal year 1994, Pacific Northwest Laboratory (PNL) participated in a Fernald-hosted effort for the evaluation of field screening tools capable of acquiring high-resolution information about the distribution of uranium contamination in surface soils in a cost- and time-efficient manner. Extensive soil sampling and laboratory analyses were performed by Fernald personnel in support of this effort, allowing the 
direct comparison of the evaluated technologies with reproducible ground truth. The site selected for investigation (Figure 5.1) was the large field north of Fernald's incinerator facility (approximately $8,000 \mathrm{~m}^{2}$ total area), where the primary source of surface contamination is the result of stack emissions from the incineration of uranium-contaminated combustibles carried by the prevailing southwesterly winds (see also, Schilk et al. 1993a).

To produce calibration standards at the Fernald facility, large aliquots of local soils were spiked and mechanically mixed to ensure homogeneity. Two calibrations were performed with the beta sensor on separate days (to demonstrate reproducibility) and the results are summarized in Figure 5.2. The individual calibrations lead to results that are quite similar, and which generate a near-ideal calibration function (i.e., a linear plot with an intercept near zero).

During the actual field-analysis phase, the sensor was placed directly on the soil surface (vegetation was cropped to within $5 \mathrm{~cm}$ ) and counts were initiated for 10 to 15 minutes at each sample location (see Figure 5.1). Sensor reproducibility was investigated by revisiting two specific field locations, referred to as standard plots \# 1 and \#2, throughout the course of the demonstration and comparing detector output as a function of time and environmental conditions. This procedure allowed PNL investigators to correct daily results, when necessary, for precipitation-induced discrepancies in the sensor response caused by intermittent rainfall ${ }^{3}$. For example, Figure 5.3 represents the observed uranium activity at standard plot \# 1 during a full day of counting and following an evening of heavy rain. In the morning and early afternoon hours, the observed activity at this location was (on average) approximately $74 \%$ of the pre-rainfall value, whereas the late afternoon measurements were roughly $90 \%$ of this baseline. Between the hours of 1400 and 1600 (i.e., the hottest part of the day), the sensor response increased linearly. This phenomenon was interpreted to indicate the evaporation of interstitial moisture from the surface soil. ${ }^{4}$ Knowledge of this phenomenon allowed investigators to scale the beta sensor response at other field locations monitored throughout this day to give results based on dry-soil conditions.

Scaled measurements from this demonstration were modelled with a commercial geostatistical software package and a two-dimensional surface activity contour map was generated (Figure 5.4). This map is consistent with site historical information, which indicates that contaminated particles originating from the incinerator stack were transported to the north and east across the field site, and uranium activity levels are observed to decrease as a function of distance from the incinerator. Further support for the beta results are provided by concurrent in situ gamma-ray spectrometry measurements and surface soil analyses, which generated qualitatively similar contour maps (Figures 5.5 and 5.6). Quantitatively, the results from these three techniques are not equivalent because of the extreme differences in the fields of view for each methodology (in situ gamma-ray spectrometry > beta sensor $>$ soil samples) and the spatial heterogeneity of the source. Hence, actual activity values at each location are highest for the soil samples, lowest for the in situ gamma-ray measurements, and intermediate for the beta detector. Despite these quantitative discrepancies, the combined data from these three technologies are well correlated (Figures 5.7 and 5.8), lending support and credence to the use of the high-energy beta scintillation sensor for field measurements of surface activity under various environmental conditions.

${ }^{3}$ Note that increased soil-moisture levels would lead to additional beta particle attenuation and a consequent decrease in sensor response for the same uranium concentration.

${ }^{4}$ Observations at standard plot $\# 2$ were consistent with these results. 


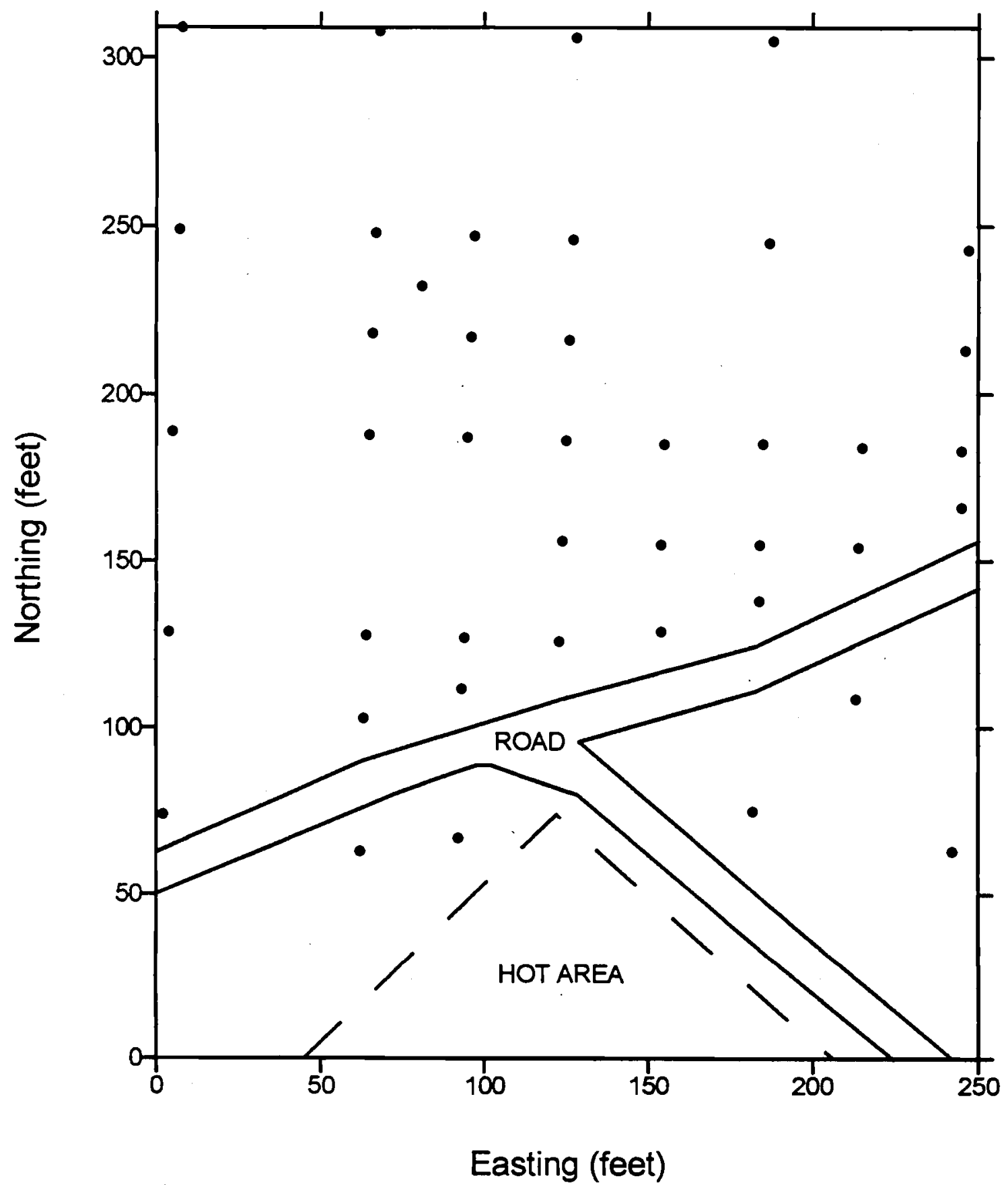

Figure 5.1. Base map for the field demonstration area, situated directly north of the Fernald incinerator area. Sample sites are indicated by solid circles; southernmost row of data points (discontinuous due to the presence of the exclusion area) are equivalent to those found immediately north of the northern fenceline surrounding the incinerator site as identified in Schilk et al. 1993a. Approximate location of the actual incinerator stack: easting $=+50$ feet, northing $=-50$ feet. 


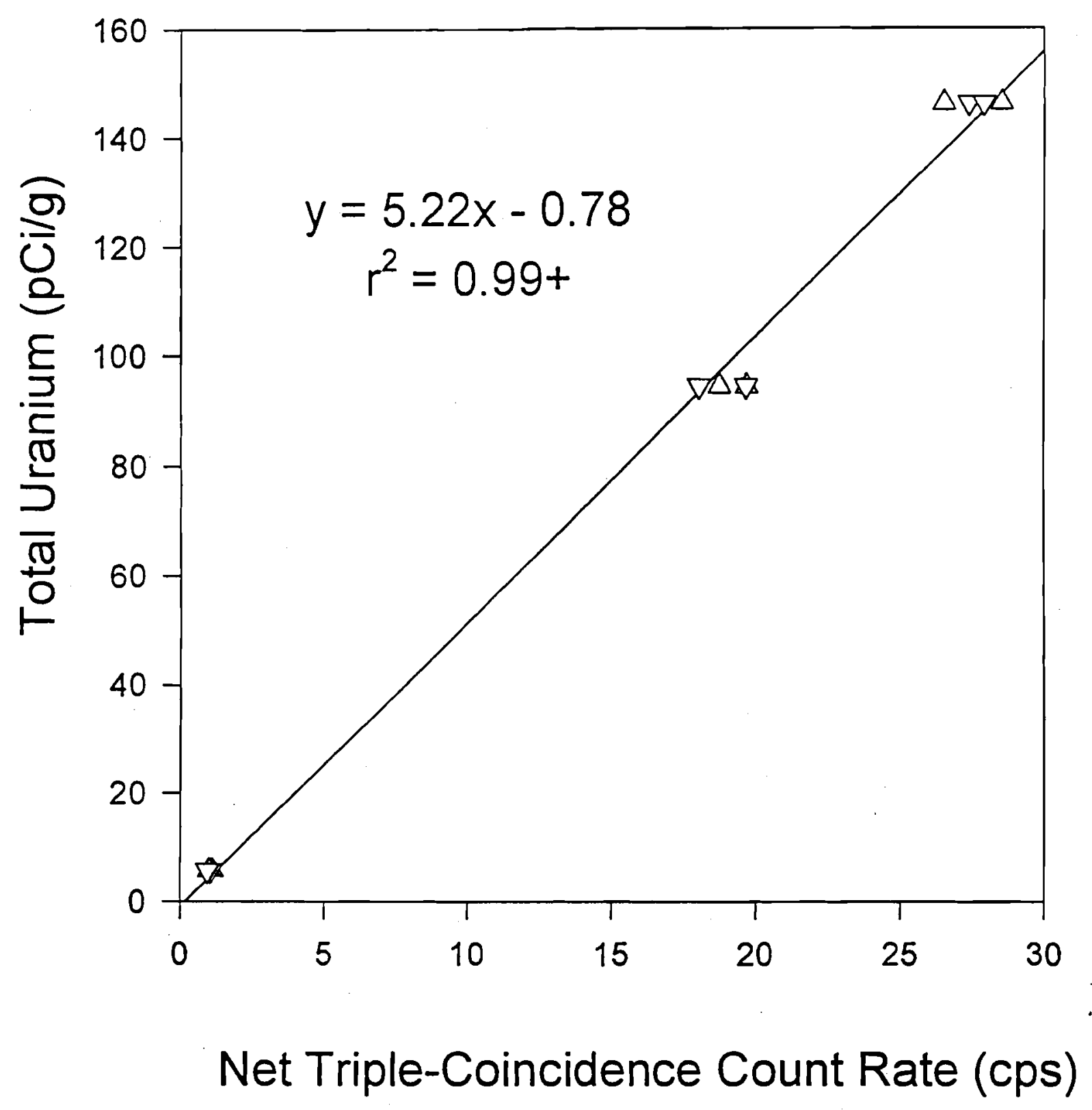

Figure 5.2. Combined results of two separate calibrations (indicated by upward- and downward-pointing triangles) performed on separate days at the Fernald incinerator site. Standards were composed of spiked local soils. The calibration curve is well behaved, with a linear slope and a near-zero intercept. 


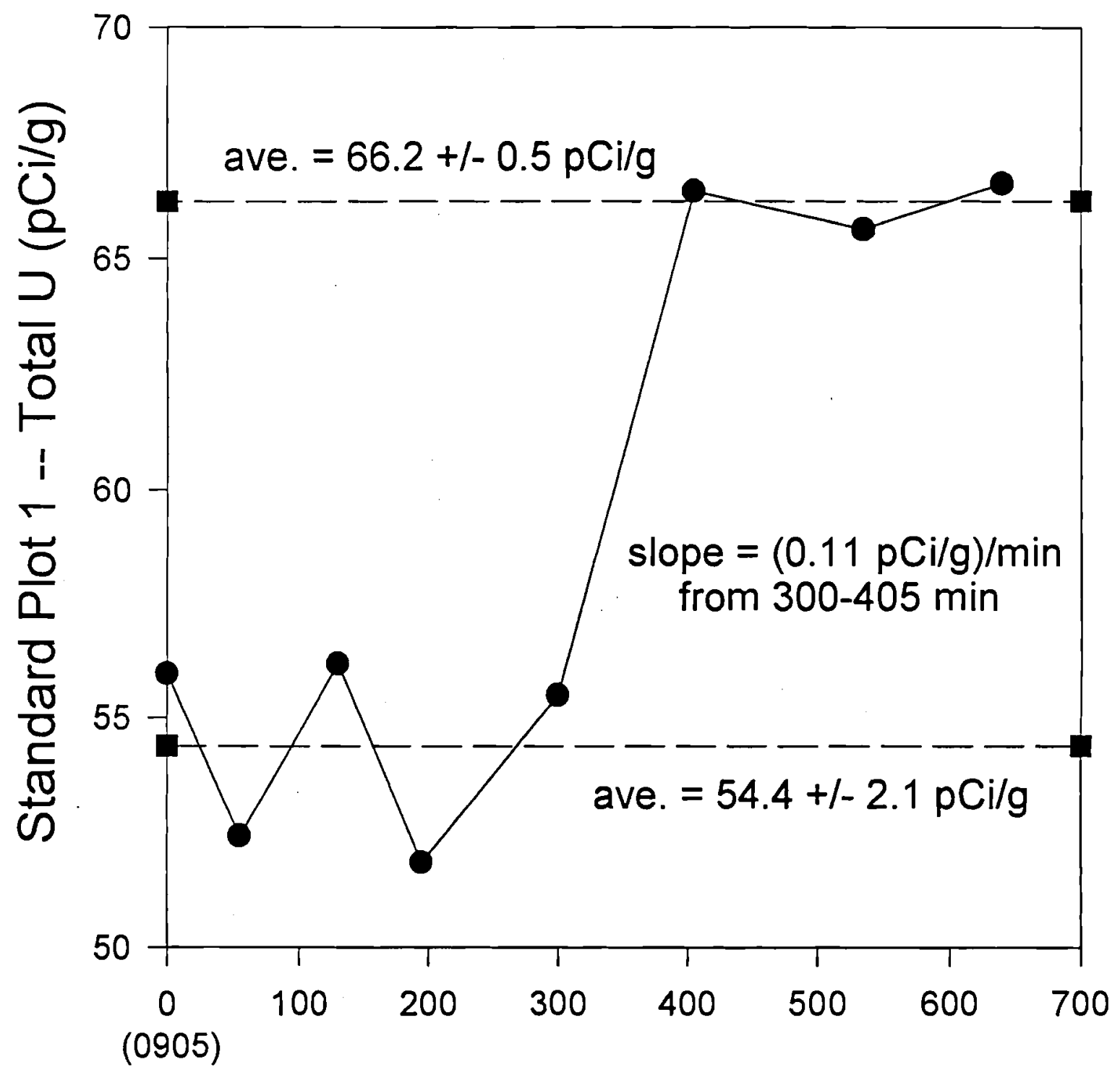

Time (minutes)

Figure 5.3. Uranium activity as a function of time at standard plot \# 1 (beginning at 0905) and following a period of heavy rain. See text for explanation. 


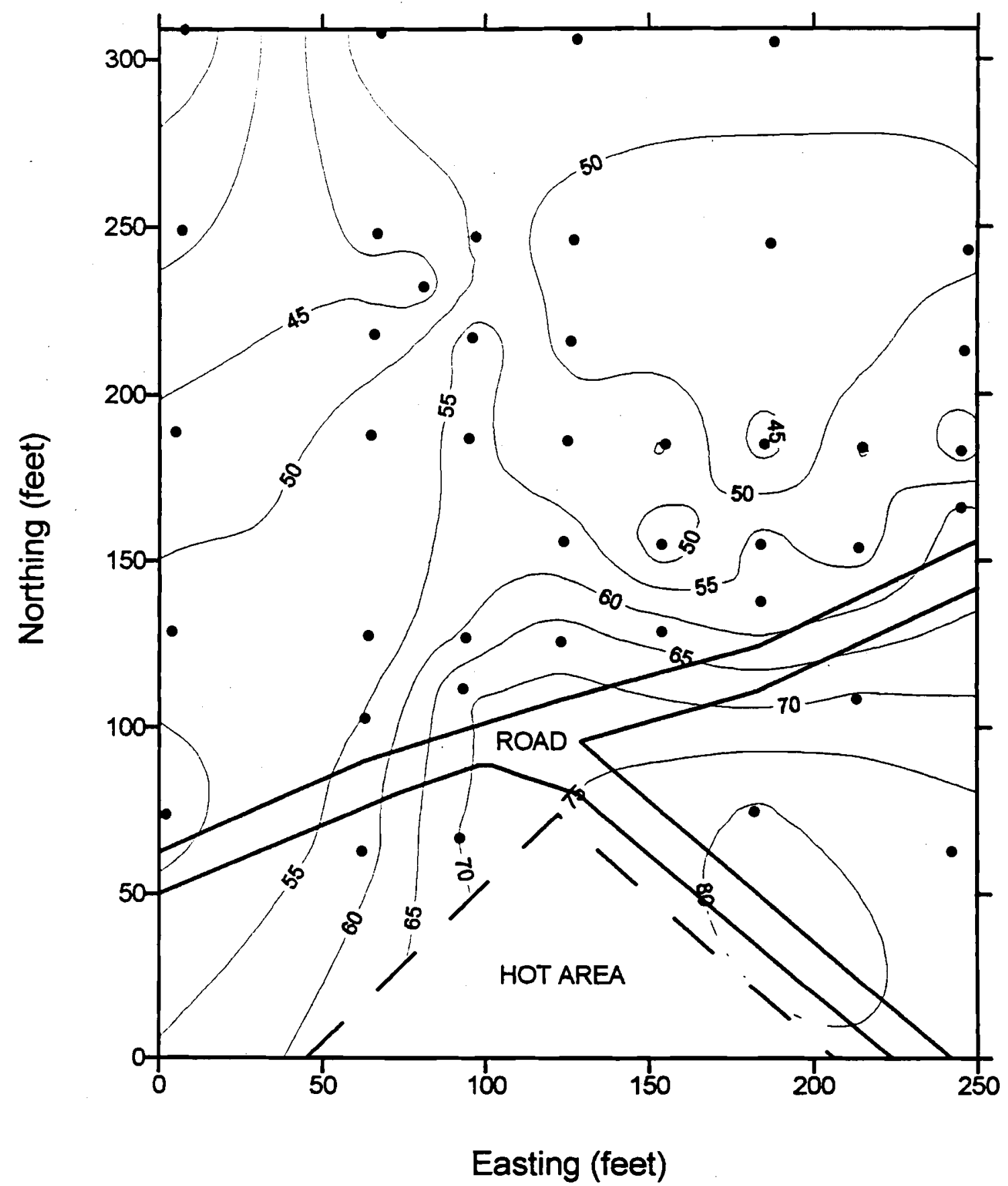

Figure 5.4. Uranium surface-activity contour map based on a geostatistical analysis of the beta sensor measurements. As predicted, the surface activity is greatest near the exclusion zone (directly downwind of the incinerator stack) and decreases in a north-northeasterly direction. 


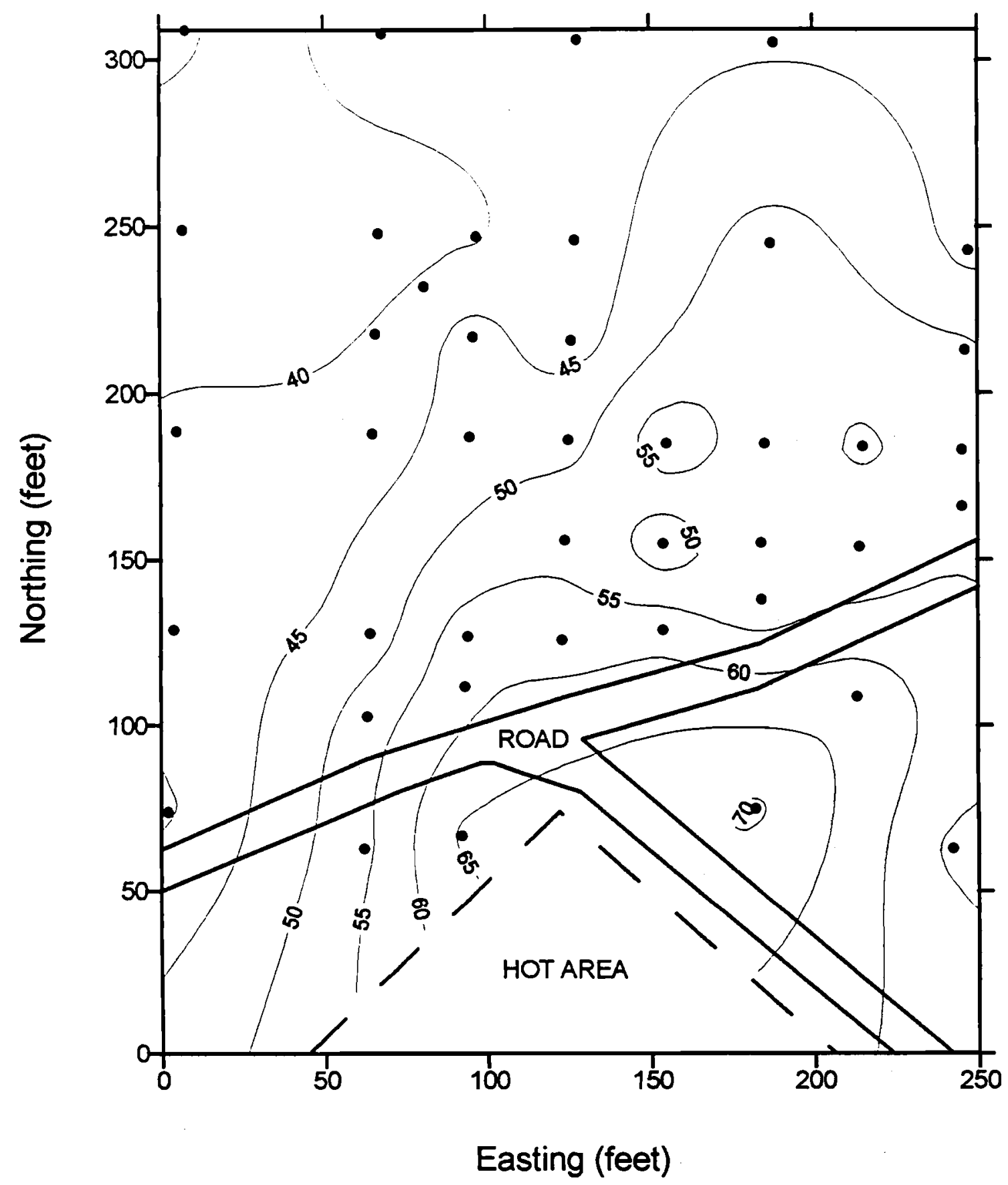

Figure 5.5. Uranium surface-activity contour map based on a geostatistical analysis of the in situ gamma-ray spectrometer measurements. Qualitatively, these results are consistent with Figure 6.1. See text for explanation of quantitative differences. 


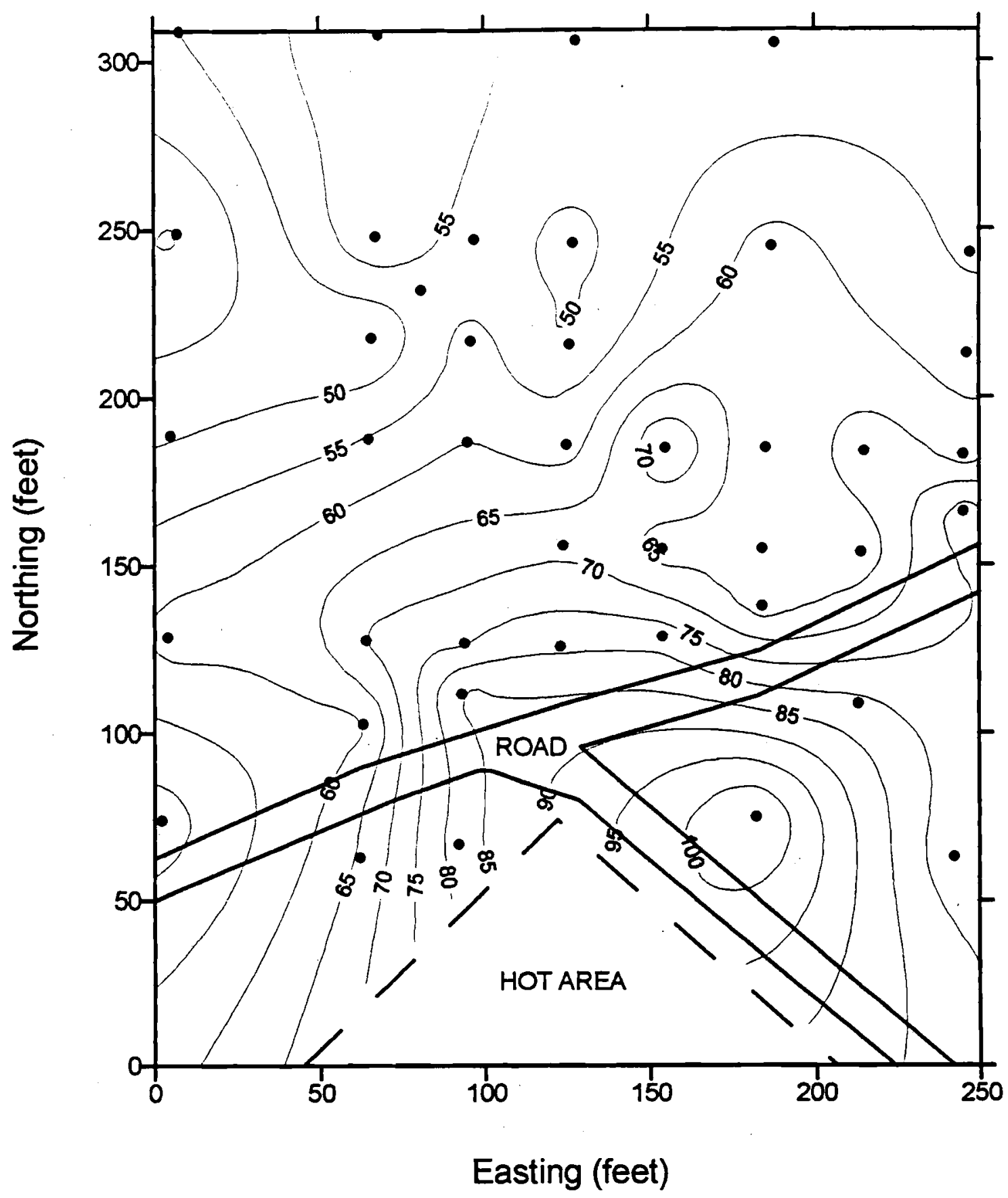

Figure 5.6. Uranium surface-activity contour map based on a geostatistical analysis of the hand sample/laboratory analysis measurements. Qualitatively, these results are consistent with Figure 6.1. See text for explanation of quantitative differences. 


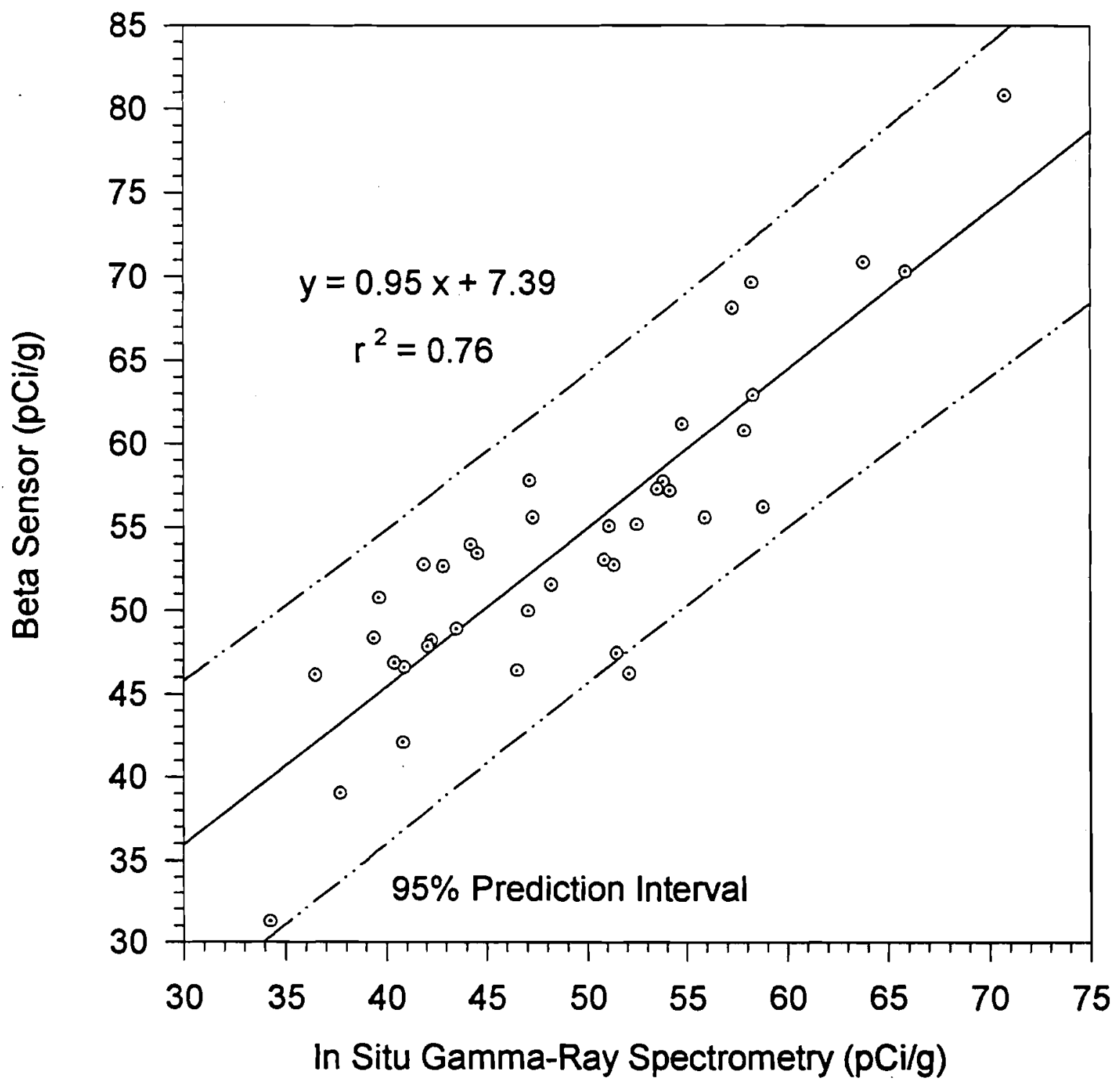

Figure 5.7. Correlation plot comparing the in situ gamma-ray measurements and the beta sensor response. The correlation coefficient ( $r$ ) is significant, indicating that the results are mutually supportive. 


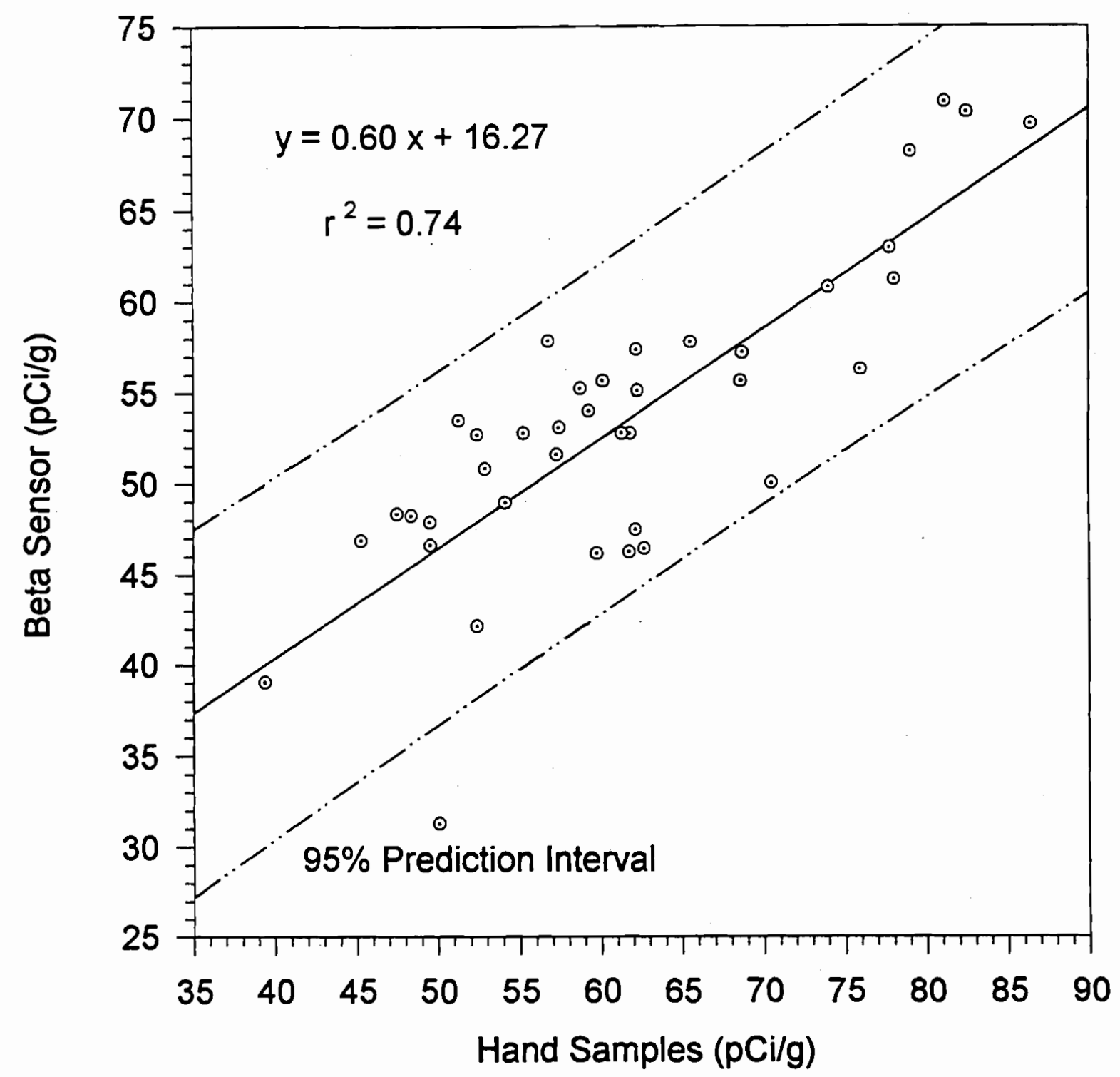

Figure 5.8. Correlation plot comparing the hand sample analyses and the beta sensor response. The correlation coefficient $(r)$ is significant, indicating that the results are mutually supportive. 


\subsection{St. Louis Airport Site (SLAPS)}

An additional field study was performed at DOE's SLAPS site near St. Louis, Missouri, in support of the Ames Laboratory's Expedited Site Characterization demonstration. This facility was used in the late 1940s to store residues from nearby uranium ore processing, which included barium sulfate cake, pitchblende and other radium-bearing materials, and contaminated scrap items.

During the second week in September, 1994, a number of sample locations within this facility were monitored with the beta and in situ gamma-ray spectrometry systems. Although soil samples were gathered at that time, assay results have not yet been provided to PNL for comparison with field analyses. 


\subsection{Conclusion and Noteworthy Accomplishments}

This document summarizes the efforts by PNL during fiscal year 1994 in fulfillment of requirements set forth in TTP \#331007 (project \#19989). These included (a) conducting tests to determine the ability to simultaneously measure long-lived fission and activation products, (b) designing/constructing a real-time sensor, (c) demonstrating this sensor under actual field conditions, (d) testing/evaluating this sensor for ${ }^{238} \mathrm{U}$ measurements, (e) packaging this sensor for conveyor-belt applications, and (f) documenting these efforts. All requirements have been successfully completed and the details of such efforts are described above in some detail. Under the direction and auspices of the DOE's Characterization, Monitoring, and Sensor Technology Integrated Program, PNL constructed a high-energy beta scintillation sensor that was optimized for the detection and quantification of uranium and strontium contamination in surface soils (in the presence of potentially interfering natural and anthropogenic radionuclides), demonstrated and evaluated this detector in various field and laboratory scenarios, and provides this summary document in completion of the aforementioned requirements.

In addition to fulfilling these requirements, PNL investigators have participated in the following meetings and conferences, and published the following documents, during the past year:

- Schilk, A.J.. 1994. "Fiber-Optic Sensor for Strontium and Uranium Characterization." Invited for presentation at the 1994 Environmental Conference, Aug. 15-19, Moscow, Russia.

- Schilk, A.J. and M.A. Knopf. 1994. "Results from the Preliminary Conveyor Evaluation of the HighEnergy Beta Scintillation Sensor at the Fernald Soil Decontamination Pilot Plant." PNL-9986, Pacific Northwest Laboratory, Richland, Washington.

- $\quad$ Schilk, A.J.. 1994. "Scintillating-Fiber Technology for the Detection of U-238 and Sr-90." PNL-SA23882, Pacific Northwest Laboratory, Richland, Washington. Presented at the 1994 Annual Meeting of the American Nuclear Society, Jun. 19-23, New Orleans, Louisiana.

- Schilk, A.J., M.A. Knopr, R.C. Thompson, and C.W. Hubbard. 1994. "Real-Time, In Situ Detection of Sr-90 and U-238 in Soils via Scintillating-Fiber-Sensor Technology." PNL-SA-24120, Pacific Northwest Laboratory, Richland, Washington. Presented at the 1994 Symposium on Radiation Measurements and Applications, May 16-19, Ann Arbor, Michigan, and to be published in Nuclear Instruments and Methods in Physics Research.

- $\quad$ Schilk, A.J., K.H. Abel, D.P. Brown, R.C. Thompson, M.A. Knopf, and C.W. Hubbard. 1994. "Selective, High-Energy Beta Scintillation Sensor for Real-Time, In Situ Characterization of Uranium-238 and Strontium-90." PNL-SA-24094, Pacific Northwest Laboratory, Richland, Washington. Presented at the Third International Conference on Methods and Applications of Radioanalytical Chemistry (MARC-IIl), Apr. 10-15, Kona, Hawaii, and to be published in the Journal of Radioanalytical and Nuclear Chemistry. 
- $\quad$ Abel, K.H., A.J. Schilk, D.P. Brown, M.A. Knopf, R.C. Thompson, and R.W. Perkins. 1994. "Characterization \& Calibration of a Large-Area Beta Scintillation Detector for Determination of Sr90." PNL-SA-23195, Pacific Northwest Laboratory, Richland, Washington. Poster presented at the Third International Conference on Methods and Applications of Radioanalytical Chemistry (MARCIII), Apr. 10-15, Kona, Hawaii, and to be published in the Journal of Radioanalytical and Nuclear Chemistry.

- $\quad$ Schilk, A.J., K.H. Abel, and R.W. Perkins. 1994. "Characterization of Uranium Contamination in Surface and Subsurface Soils." PNL-SA-23787, Pacific Northwest Laboratory, Richland, Washington. Journal of Environmental Radioactivity, in press.

Negotiations are currently underway with the BICRON Corporation of Newbury, Ohio (the vendor that produces the scintillating fibers used in the beta sensor), to license this detector technology in anticipation of the mass production and commercialization thereof. BICRON has also expressed strong interest in licensing the custom electronics developed in conjunction with this year's efforts for use in their popular scrap-steel monitoring systems around the world. A non-disclosure agreement for the transfer of these technologies has been approved. 


\subsection{References}

Perkins, R.W. and U.P. Jenquin. 1994. "Identification of Radionuclides of Concern in Hanford Site Cleanup." PNL-10060, Pacific Northwest Laboratory, Richland, WA.

Riley, R.G. and J.M. Zachara. 1992. "Chemical Contaminants on DOE Lands and Selection of Contaminant Mixtures for Subsurface Science Research." DOE/ER-0547T, U.S. Department of Energy, Washington, D.C.

Schilk, A.J., R.W. Perkins, K.H. Abel, and R.L. Brodzinski. I993a. "Surface and Subsurface Characterization of Uranium Contamination at the Fernald Environmental Management Site." PNL-8617, Pacific Northwest Laboratory, Richland, WA.

Schilk, A.J., R.W. Perkins, K.H. Abel, R.L. Brodzinski, D.P. Brown, R.C. Thompson, and M.A. Knopf. 1993b. "Quantitative In Situ Uranium Contaminant Mapping Using High-Resolution Gamma-Ray Spectrometry and Beta Scintillation Counting." in Proceedings of the ER '93 Environmental Remediation Conference, October 24-28, Augusta, Georgia, pp. 155-158.

Schilk, A.J., K.H. Abel, and R.W. Perkins. 1994. "Characterization of Uranium Contamination in Surface Soils." Journal of Environmental Radioactivity, in press.

Schilk, A.J. and M.A. Knopf. 1994. "Results from the Preliminary Conveyor Evaluation of the High-Energy Beta Scintillation Sensor at the Fernald Soil Decontamination Pilot Plant." PNL-9986, Pacific Northwest Laboratory, Richland, WA. 
' 
PNL-10483

UC-606

\section{Distribution List}

No. of

Copies

Offsite

12 DOE/Office of Scientific and Technical Information

20 C.B. Purdy

U.S. Department of Energy I9901 Germantown Road

Germantown, MD 20874

DOE/Office of Technology

Development

C. W. Frank

Forrestall Building

1000 Indpendence Ave SW

Washington, DC 20585

P. Wang

Ames Laboratory

106 Spedding Hall

Ames, IA 50011-3020
No. of

Copies

Onsite

1 DOE Richland Operations

Office

D.E. Trader

18 Pacific Northwest Laboratory

A.J. Schilk (5)

C.W. Hubbard

M.A. Knopf

R.C. Thompson

D.E. Robertson

S.C. Slate (3)

Publishing Coordination

Technical Report Files (5) 
